\title{
Area-Based Participatory Action Learning of Social Studies Pre-service Teachers to Develop Indigenous History Learning Resources for Diversity Students in Northern Thailand
}

\author{
Charin Mangkhang ${ }^{1}$ \\ ${ }^{1}$ Faculty of Education, Chiang Mai University, Thailand \\ Correspondence: Charin Mangkhang, Faculty of Education, Chiang Mai University, 239 Huay Kaew Rd, Suthep, \\ Mueang District, Chiang Mai, 50200, Thailand. E-mail: charin.mangkhang@cmu.ac.th
}

Received: February 1, 2022

doi:10.5539/hes.v12n2p20
Accepted: March 5, 2022 Online Published: March 8, 2022

URL: https://doi.org/10.5539/hes.v12n2p20

\begin{abstract}
The research aimed to 1) study the needs in developing indigenous history for diversity students in Northern Thailand, 2) develop indigenous history learning resources for diversity students in Northern Thailand through area-based participatory action learning of social studies pre-service teachers, and 3) distill learned lessons obtained from developing indigenous history learning resources through area-based participatory action learning of social studies pre-service teachers for diversity students in Northern Thailand. The methodology of the research was based on Participatory Action Research (PAR). The sample in the research consisted of 1) community leaders, monks, school administrators, folk philosophers, and youth representatives accounting for 22 people; 2) 10 social studies pre-service teachers; 3) 8 indigenous mural painters, making a total of 40 people. The instruments used in the research were 1) unstructured interview forms, 2) forms of synthesizing knowledge to moral creativity, 3) validity assessment forms of indigenous history data, and 4) focus group discussion recording forms. Qualitative data was analyzed based on content analysis and the presentation was in the form of descriptive analysis. Study results revealed that:

1) From the area-based action on the legend of Viang Malika and Phra Nang Malika from history in the educational sandbox of Chiang Mai province, it was found that the community has demand in terms of developing learning resources telling its indigenous history through the temple which is the common area in the community. The demand is to present indigenous history which is part of the historical development of the Lanna Kingdom in terms of business, politics, administration, education, religions, and the environment including women's roles as governesses or kings. This shows feminist concepts appearing on the page of indigenous history and reflects equality in stepping over physical limitations of the body (disability). The frame limiting gender is destroyed through the history of leaders and kings in indigenous history has influenced the development of the history of the historical development of the Thai local society up to the present time. 2) Developing indigenous history learning resources through area-based participatory action learning of social studies pre-service teachers for diverse students in Northern Thailand has brought about indigenous history learning resources integrating cooperation between universities, communities, temples, and schools. Indigenous history learning resources have been brought about, which helps promote quality learning management. And 3) From distilling learned lessons obtained from developing indigenous history learning resources through area-based participatory action learning of social studies pre-service teachers for diversity students in Northern Thailand, the important social studies competency of social studies pre-service teachers for 4 aspects were found. This is called the competency of area-based social studies learning or so-called "VCAP" consisting of 1) Value Domain, 2) Cognitive Domain 3) Affective Domain and 4) Psychomotor Domain, which helps promote occupational competency of pre-service teachers to be more efficient.
\end{abstract}

Keywords: area-based participatory action learning, indigenous history learning resources, education sandbox, social studies pre-service teachers, equity education

\section{Introduction}

Philosophy of Educational Makerspaces, the concept of Buddhism Intelligence Education, and the Multiperspective concept explain phenomena in the democratic society requiring citizens who can interpret data 
based on critical thinking and a variety of occurring phenomena. Society has diversities consisting of cultural diversities, different groups, and different interpretations. To teach citizens for preparing them to understand the world in which they live, teaching must be designed with various viewpoints. History is a complex thing and should be taught with various viewpoints because there is no true historical content. This depends on the complicated context of time and space. Presenting various historical viewpoints makes use of critical thinking. Students as future citizens must learn about historical sources to know what are facts, what is interpretation, what are pieces of evidence, what is well-discussed interpretation, and what is the main interpretation contradicting facts. Learners must understand and practice the concept of various viewpoints, various historical data, especially for historical data with contradicting records. This is the point where citizens who are skillful thinkers originate from. Moreover, they must think critically and learn questioning with available data to assess data credibility in finding answers to the questions posed by learners through data analysis, data selection from sources, comparing other viewpoints, assessment, and making decisions in lifelong learning. This process is working with several viewpoints leading to the development of critical thinking (Kurti, Kurti, \& Fleming, 2014; Bickmore \& Parker, 2014; Somdej Phra Buddhakosachan (P.A. Payutto), 2019; Mangkhang, Wannapaisan, Jarupongputtana, \& Kaewpanya, 2021).

From the concept of the fourth for sustainable development goals (SDGs) in supporting equal and through education and promoting lifelong learning for everyone, to succeed covers quality education. This reinforces the proven belief that education is one of the driving forces with efficiency for sustainable development. Moreover, there are also some objectives to organize equal occupational training with reasonable prices and to remove sexual inequalities and differences to succeed in reaching universal principles for higher education with qualities and developing learning skills to reach their local communities. This relies on the environment as an important lesson in integrating learning the science of other fields. One of the operation approaches is building and upgrading equipment and educational instruments sensitive to children, the disabled, and gender. Moreover, there should be a safe and violence-free learning environment, covering and being effective to everyone. The objective is to build a guarantee so that every learner will receive the knowledge and skills required for promoting sustainable development. This also includes education for sustainable development and having a sustainable way of life through cultural diversities and cultural participation in sustainable development (United Nation, 2015; Mangkhang, 2021).

The vision of the social studies curriculum for the basic education level of B.E. 2551 has been reviewed to find the method of developing every learner as the national power to be human beings with physical, knowledge and virtuous balance, the conscience of Thai citizenship, and being world citizens holding on to democracy with the King as the head of the state. This also includes having basic knowledge and skills, and attitudes required for education, occupations, and lifelong education. Learners are focused mainly based on the belief that all people can learn and develop themselves according to their potential (Ministry of Education, 2008). Regarding building opportunities and equalities according to the 20-year national strategy (B.E. 2561-2580), there are important goals of development placing importance on pulling energy from sectors, namely private sectors, the civil society, local communities to participate in driving together. This can be done by supporting public integration in thinking and taking actions mutually for the public (Office of the National Economics and Social Development Council, 2018). Therefore, educational management must focus on integrating area-based identities in the community to be the foundation of social science learning management with a variety of learning dimensions such as community history, community geography, ethnical cultures, Buddhist art, ecological cultures, etc.

The concept of the process of studying history vertically or iceberg history. This is the learning concept and increases viewpoints in studying in-depth history from what is appearing. For teachers and students, they must have knowledge and understanding about historical stories happening in the past. Historical stories have been recorded. Certain historical stories have been propagated through historians' works. This shows the reflection of stories in the past and stories built with references of data sources or historical shreds of evidence obtained from findings to be analyzed further. History is the platform for practicing critical thinking and there are also references from reliable data sources. Historians interpret those data to be presented as their conclusion. The mentioned process will have more qualities if students use data sources and historians' works to develop skills of critical thinking. Critical thinking is the quality thinking process with the goal of correctness, clarity, pertinence. There is logical revision and justice whereby teachers and students must understand the process and always consider the thinking process of their own. This is since historical memories are fragile. Implementing knowledge to integrate schooling management must be cautious and prepare the community to approve knowledge (Black, 2011; Mangkhang, Wannapaisan, Jarupongputtana, \& Kaewpanya, 2021) to promote educational equalities leading to education for sustainable development. 
Indigenous history or local history is telling facts of history through story-telling o indigenous people related to education, law, administration, politics, or history from the perspective of indigenous people. The indigenous community is the community with a history connecting to territories. Moreover, it is an ethical identity existing as local beautiful cultural customs. It is the place where there is the process of studying community history or village history based on the data from legends, stories, and history of villages transferred through sayings of villagers who are people in the district. It is the process of studying social history focusing on masses who are the majority of the people without formal power, these people do not have an opportunity to receive modern education. This is an important component to make it possible to see the movement of society. In conclusion, indigenous history is the study of the society of masses in the district from the past to the present time by looking through local data and shreds of evidence mainly. It is the way of seeing the district from the bottom. Studying indigenous history helps see the picture of the society at the micro level more clearly. Therefore, it is interdisciplinary programmed learning which helps open up new dimensions beyond learning history coming from the state. It is the concept of a historical iceberg. History is mostly suppressed and deleted from memory to become the history of forgotten memories which is not mentioned about. Moreover, studying indigenous history brings about historical knowledge with memories and does not go against the ways of the local community. This leads to the creation of empirical works presenting valuable historical stories to become learning resources and transferring them to the next generation (Daes, 2008; Mahuika, 2019; Mangkhang et al., 2021).

The area of memories on murals is art and culture which can be used as witnesses of national time and development, making us know the evolution of the progress of the Thai society in eras. This has been created and conveyed as stories in murals full of exquisite harmony bringing about aesthetic arts (Manichot, 1986). The fact that murals were painted based on true events in the past is useful for studying Buddhism, history, archaeology, dressing, building shelter, traditions as well as amusement

(Department of Fine Arts, 1981). They are also important pieces of evidence for education, national and local heritage full of values. It is a matter of admiring religions, literature and promoting the King's popularity for decorating buildings. The objective for this is to add beauty to building walls, to convey the support of Buddhist teaching, to show talent, and express the emotions of artists. It is the faith of the painter in religion. There is a complex, meticulous, neat, and delicate process of building. The work originates from the faith and industriousness of the muralist who creates mural works. It is the matter of recording stories and traces in the past. The mural is used to tame the mind because stories in the mural painting are valuable Buddhist doctrines and the symbol of national progress. They are useful for studying history, showing races, arts, architecture, social science, ecology, archaeology, traditions, ideology. They are Buddhist textbooks and are useful to the economy of the country (Manichot, 1986). Therefore, the mural painting is a work of art much suitable for transferring historical stories and it can be used as a learning resource of indigenous history as well.

The learning resource of indigenous history is the learning resource that focuses on building educational equalities by presenting results of studying community history or unwritten village history. It is the memory from legends, stories, and history of villages transferred through saying of villagers who are people in the district. Therefore, the data obtained come from the experiences of the researcher who conducted the study in the community and then arranged the data obtained from saying about legend background of memories passed on to generations (Wittayapak, 2003). This made it possible to understand the diversities of cultural ways, experiences, and different systems of communities. Community diversities can be counted from the village level up to the common section in terms of culture and experiences from the same past. Without the root of community history, the community usually loses the energy of adaptation eventually. Moreover, without common conscience of being a "community", a number of problems will occur. Indigenous history will combine people in the community to have a common conscience in terms of having the common root in building indigenous history and living together peacefully.

Therefore, social studies operation for sustainable development must focus on developing teacher competency for local education, increasing capabilities of participatory self-reliance development and self-management with knowledge and virtues, ethics without affecting life qualities and the environment. This must be in line with the vision of Thailand, namely security, wealth, and sustainability. Regarding educational management focusing on increasing capabilities of the local community, learning only one science maybe not be enough for current learning management. A variety of sciences and cooperation in every science must be relied on to design learning which corresponds to world citizenship development in the new century. The approach of transdisciplinary learning is the new form of learning and solutions involving cooperation among sectors of the society, including educational institutes to correspond to complex challenges through mutual learning. All students' knowledge will increase and lead to learning about the complex society. The objective of 
transdisciplinary learning is to understand the current world in every complexity instead of focusing on only one part. Moreover, transdisciplinary learning is also building the cooperation network of efficient area-based educational management, which brings about the common area of learning together with every sector (Kaewpanya, Mangkhang, Dibyamandala, 2021). This can integrate knowledge from the community to design (Community-Based Transdisciplinary Learning in Social Studies: CBTDLSS).

The area of Viang Malika is a small ancient city located in the district of Mae Ai, Chiang Mai province. It is characterized according to the form of the foothill plain where the city is located. Therefore, the city wall and the moat wind along the geographic area. The Viang Malika legend and Phra Nang Malika are the history in the area of Mae Ai district, Chiang Mai province connecting to the history of Fang city. Phra Nang Sam Piew is part of the historical development of the Lanna Kingdom in terms of commerce, politics, administration, relations, etc. Moreover, women's roles are also mentioned as governesses or kings showing the feminism concept appearing in the history page and influencing development in the subsequent era of the Lanna Kingdom.

Therefore, from the above-mentioned statement, there is no study on the history of Phra Nang Malika in the educational sandbox of Chiang Mai province regarded as part of the historical development of the Lanna Kingdom handed down to the present time. Studying indigenous history will bring about the learning process to build educational equality through the social process with the cooperation of the school, the community, and the university. The objective is to develop indigenous history learning resources, which can be used in schooling management, organizing learning activities in the educational sandbox of Chiang Mai province. This can lead to developing qualities of area-based education according to the main goal of sustainable development further.

\section{Method}

This research was conducted in the form of Participatory Action Research: PAR through collecting and analyzing data obtained from analysis of documents, interview forms and focus group discussion. Study results were presented in the form of descriptive analysis.

\subsection{Population and Samples}

The population used in the study consisted of 3 main target groups: (1) community leaders, villagers, monks, school administrators, teachers, folklore intellectuals, and youth representatives: (2) social studies pre-service teacher, Faculty of Education, Chiang Mai University: and (3) indigenous mural painters whereby the researcher selected samples for data collection convenience with following details

Samples in the research are:

(1) Community leaders, villagers, monks, school administrators, teachers, folk philosophers and youth representatives accounting for 22 people based on snowball sampling;

(2) Social studies pre-service teacher, Faculty of Education, Chiang Mai University accounting for 10 people based on volunteer sampling and they registered for the course 071418- Social Studies Independent Study of Semester 1 of the academic year 2021;

(3) Indigenous mural painters accounting for 8 people based on purposive sampling

\subsection{Research Instruments}

Among the data collecting methods are the following:

(1) Unstructured interview forms

(2) Forms of synthesizing knowledge to mural creativity

(3) Validity assessment forms of indigenous history data

(4) Focus group discussion recording forms

\subsection{Methods of Data Collection}

Documentary study was conducted by collecting data for documents, books, journals in terms of theories, concepts and related research works in order to use the obtained data to support the analysis of educational issues, including the study on basic data to be used as guidelines in studying field data.

Field study was classified into 3 periods as follows:

Period 1 Situational Analysis refers to collecting qualitative data by synthesizing documents and related action research and entering the field to collect samples in the research. The instruments used were unstructured interview forms on the needs in developing indigenous history learning resources for diversity students in Northern Thailand. 
Period 2 Design and Development refers to collecting qualitative data by designing and developing murals regarding the indigenous of Phra Nang Malika. Checking qualities and finding suitability of the developed learning resources were conducted by checking with the people involved. The instruments used were forms of synthesizing knowledge to moral creativity and validity assessment forms of indigenous history data.

Period 3 To distill learned lessons obtained from developing indigenous history learning resources through area-based participatory action learning of social studies pre-service teachers for diversity students in Northern Thailand whereby the instrument used was focus group discussion recording forms.

\subsection{Data Analysis}

Regarding qualitative data, the research team analyzed data according to the educational goal based on the method of data analysis through interpretation obtained from document analysis, interviewing and focus group discussion in order to summarize issues according to data groups. Moreover, relationships were also analyzed.

\section{Results}

For the research at this time, the researcher classified the data obtained from the study and presented research results according to the determined objectives. Research results can be summarized as follows:

3.1 Conducting the Area-based Action Regarding the Makika Legend and Phra Nang Malika from History in the Chiang Mai Education Sandbox Revealed that the Community has the Demand to Develop Learning Resources Telling their Indigenous History through Temples which are Common Areas in the Community

The demand is to present indigenous history which is part of the historical development of the Lanna Kingdom in terms of business, politics, administration, education, religions, and the environment including women's roles as governesses or kings. This shows feminist concepts appearing on the page of indigenous history and reflects equality in stepping over the physical limitations of the heroine disability. The frame limiting gender is deconstructed through the history of leaders and kings in indigenous history has influenced the development of the history of the historical development of the Thai local society up to the present time.

3.2 Results of Develop Indigenous History Learning Resources for Diversity Students in Northern Thailand through Area-based Participatory Action Learning of Social Studies Pre-service Teachers

The researcher conducted the research together with social studies pre-service teachers and Indigenous mural painters in designing the mural painting. After that, the draft of the mural paintings regarding the history of Phra Nang Malika of Viang Malika in Lanna was inspected and the researcher received suggestions from the community. The researcher together with professional teacher students and indigenous mural painters improved the draft of the mural paintings regarding the history of Phra Nang Malika of Viang Malika in Lanna according to the received suggestions. Them, they used the draft of the mural paintings the mural painting regarding the history of Phra Nang Malika of Viang Malika in Lanna to build complete mural paintings the mural painting regarding the history of Phra Nang Malika of Viang Malika in Lanna at Mae Ai Luang Temple, Mae Ai district, Chiang Mai province with following details: 
Table 1. Details of mural paintings regarding indigenous history of Phra Nang Malika

\begin{tabular}{ll}
\hline Picture name & Full picture \\
1. Royal dream of \\
giving birth to Phra \\
Nang Malika, \\
Chiang Mai
\end{tabular}

2. Royal giving birth to Phra Nang Malika,

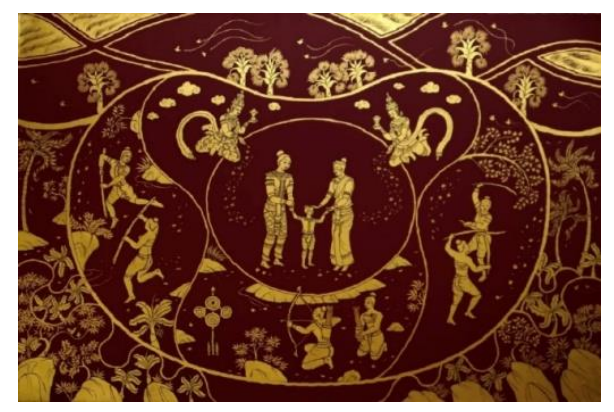

\section{Viang Malika}

Land of Buddhists,

Chiang Mai

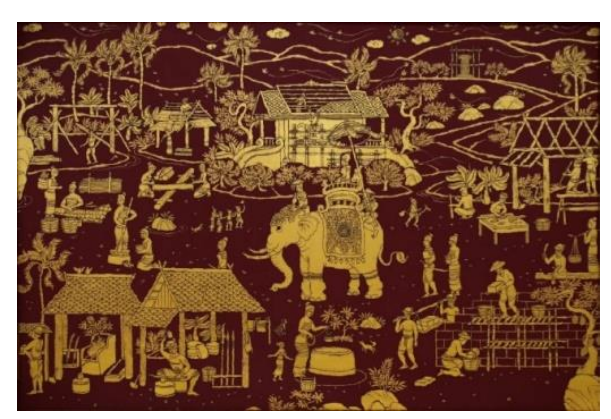

4. Toponymy of the Land: Mae

Ai, Chiang Mai
Social studies concepts

The main concept of history with social studies concept as follows:

- Time

- Era

- Origins

- Civilization

- Consequences

- Culture

The main concept about Global Education with social studies concept as follows:

- System

- Human Right

- Cooperation

- Communication

- Peace

The main concept about geography with social studies concept as follows:

- Space

- Place

- Location

- Population/Patterns

- City/Country/State

- Resources

- Bounder/Rural

The main concept about geography with social studies concept as follows:

-Human-Environment Interaction

- Culture

- Adaptation

- Diffusion

- Population Density

- Connections 


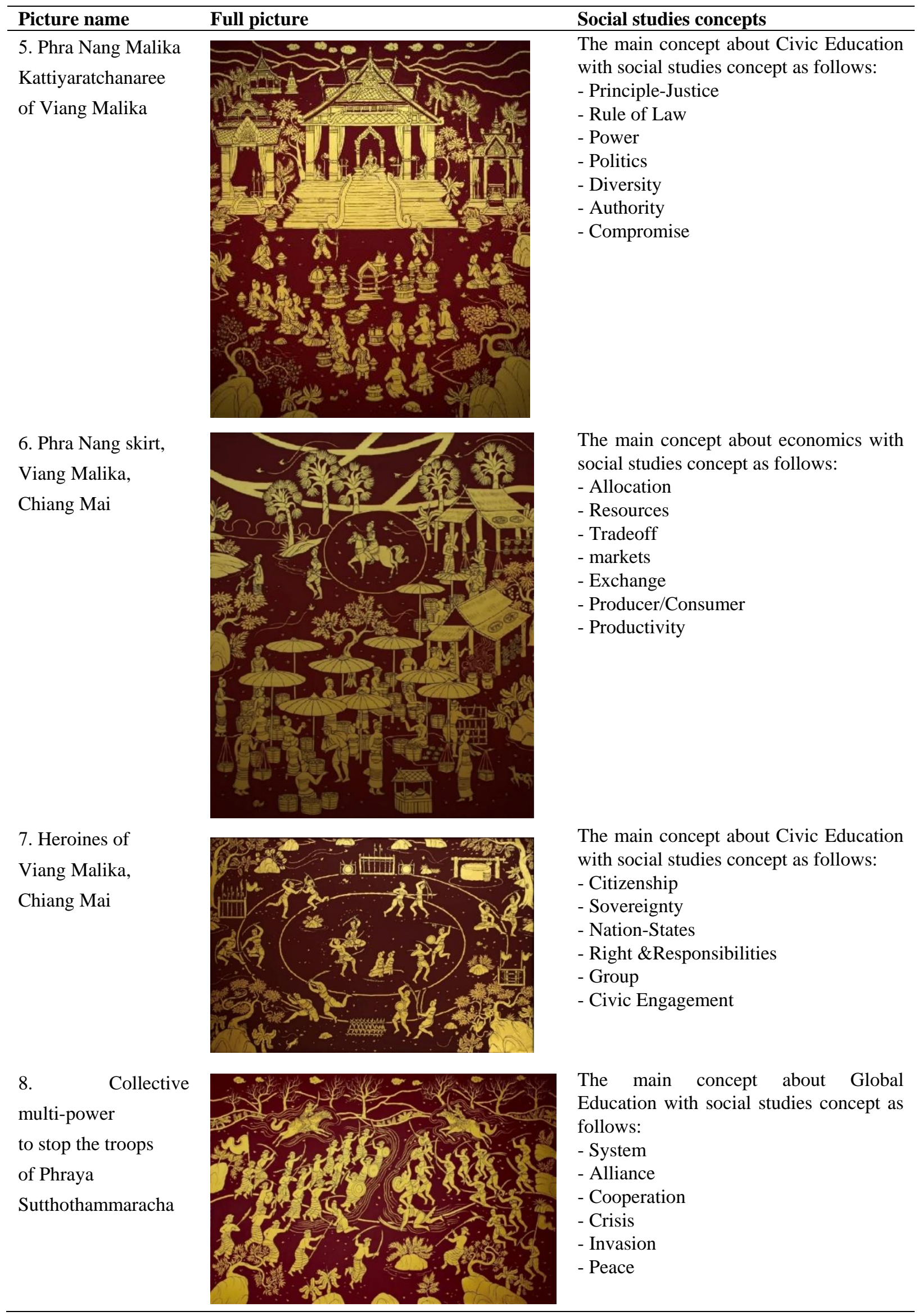




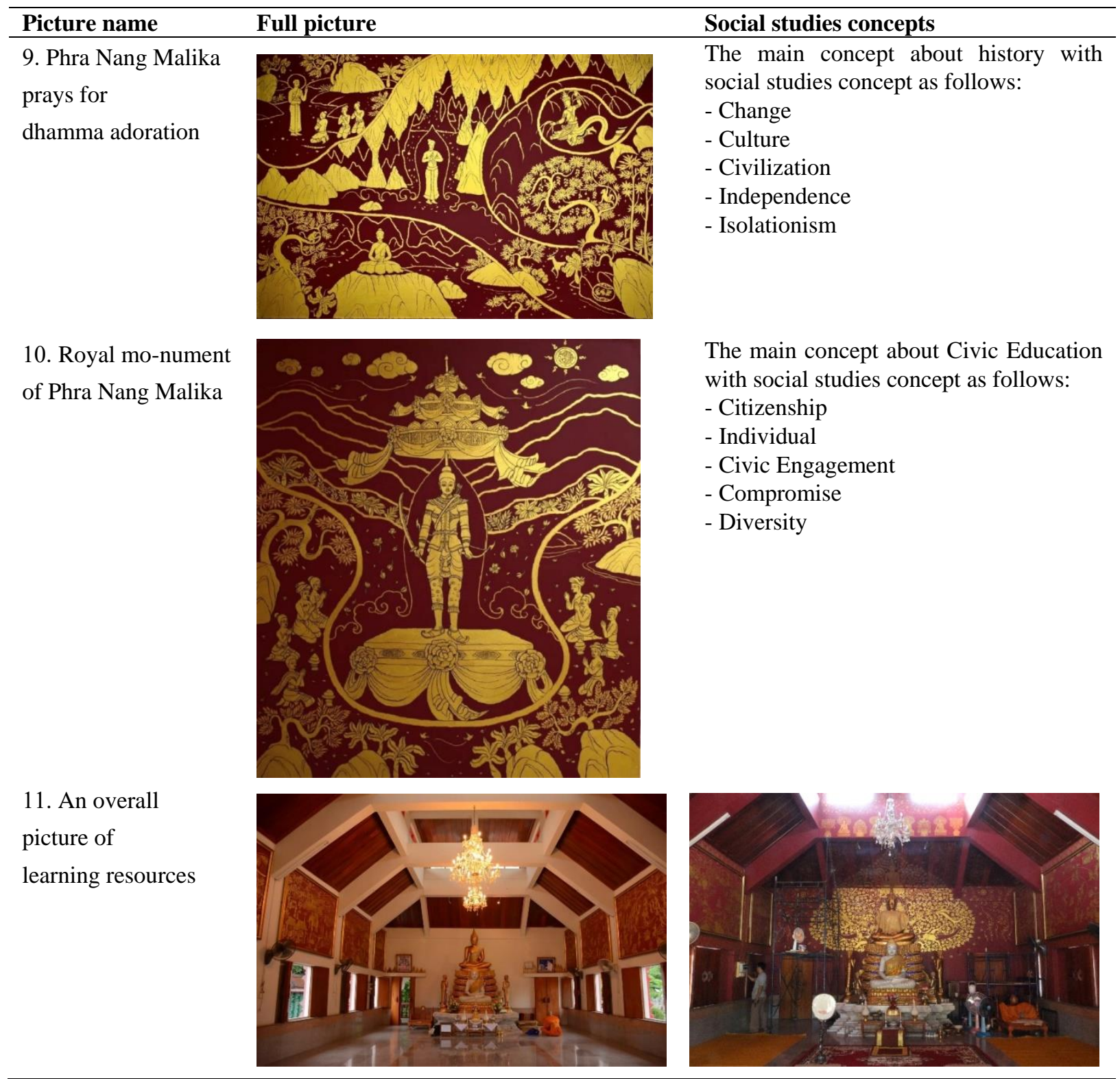

Sources: Charin Mangkhang

3.2 Distill Learnt Lessons Obtained from Developing Indigenous History Learning Resources through Area-based Participatory Action Learning of Social Studies Pre-service Teachers for Diversity Students in Northern Thailand

Made a discovery of the social studies pre-service teachers competence for 4 aspects so-called the competency of area-based social studies learning or "VCAP" consisting of 1) Value Domain, 2) Cognitive Domain 3) Affective Domain and 4) Psychomotor Domain with following details:

Table 2. Shows details of the social studies pre-service teachers competence distilled from developing in indigenous history learning resources through area-based participatory action learning of social studies pre-service teachers for diversity students in Northern Thailand

\begin{tabular}{lll}
\hline $\begin{array}{l}\text { Competency of } \\
\text { area-based social } \\
\text { studies learning }\end{array}$ & Characteristics of global citizenship & Skills of area-based social studies \\
\hline 1. Value Domain & $\begin{array}{l}\text { Expression for ethical decision-making by } \\
\text { being aware of things which one gives values } \\
\text { to of one's own without using one's values to }\end{array}$ & $\begin{array}{l}\mathbf{1 .} \text { Value of happiness: Telling about happiness form creative and } \\
\text { place and learning to behave properly in the public area }\end{array}$
\end{tabular}




\section{Competency of Characteristics of global citizenship area-based social studies learning}

judge other people. This is the approach of decision-making distilling conscience to rank behavioral expressions suitable in living together in the society

2. Cognitive Expression based on higher-order thinking Domain

3. Affective Expression of people regarding cleverness, Domain
This starts with the fact that people can memorize facts or have knowledge and memory about something and then the knowledge is made understood and used for analysis, assessment, and creativity.
Skills of area-based social studies

2. Humanizing sustainability: respect culture, diversity intellectual and select folklore knowledge in presenting data which everyone can access and to create a sustainable space of peaceful

3. Awareness: Being aware of local resources in terms of life-supporting resources and intellect and knowledge resources in the past of the district without termination in the past but having influences in the present time to the future

4. Acknowledgement: Appreciate interesting indigenous history which is worth studying and propagate historical data, build conscience in conserving historical areas and create being a community. Indigenous history also builds common conscience for the community to be strong.

5. Appreciate: Appreciate the process of developing learning resources at this time, build conscience and being aware of data use. This is due to the fact that knowledge management for presentation is quite sensitive in reproduction causing bias of knowledge and memory. Therefore, data presentation requires emphasis on being local with respect to the community and local spirit as well.

1. Remember: Put important events in sequence by remembering facts mutually connected through time

\section{2. knowledge and Comprehension:}

Know and understand indigenous history through story-telling history and history from mural painting

3. Define: Define new knowledge in indigenous history, making it possible to see a variety of the knowledge set of people in the community and government and private agency. This requires skills in managing knowledge obtained through data collection. Analyze and arrange the data set to be consistent with between history, storytelling history and mainstream history which can be referred to in order to develop data to be new thinking sets to the district.

4. Application: Propose the concept in building indigenous history knowledge in other areas

5. Analysis and Synthetic: Skills in organizing the data obtained from data collection, arrange the data by putting occurring events in order continuously and analyze the data, then present them to the public

6. Evaluation: Assess the data from the district to build new knowledge to cultural history in the multicultural context

7. Development: Develop knowledge of indigenous history of the folk wisdom community reflecting through way of life and faith. Moreover, the thinking process of working and the participatory working process with respect to villagers' feelings are also developed.

8. Transformative: Being able to build new memorized images in learning their own indigenous history

9. Reinvention: Create the method of learning indigenous history which is the learning resource developed to build data sets in learning, build the thinking process in creating communities and build cultural values to the community

1. Value: Being proud of having an opportunity to acknowledge, listen to indigenous history, leading to develop and extend the obtained knowledge further, create works valuable to learning in terms of knowledge, attitudes, including the process of passing on 


Competency of Characteristics of global citizenship Skills of area-based social studies
area-based social
studies learning

that, the valuable things are organized beautiful cultures of the community

systematically and then built to be 2. Organize: Managing situations and adapting to be familiar with characteristics of people eventually.

$\begin{array}{ll}\text { 4. Psychomotor } & \text { Expression to things, starting from imitation, } \\ \text { Domain } & \text { conforming, doing things correctly, doing } \\ & \text { continuously and doing naturally and solving } \\ & \text { problems creatively }\end{array}$

4. Psychomotor problems creatively

Sources: Charin Mangkhang

villagers in data collection

3. Conscious: Having consciousness and responsibilities in developing indigenous history learning resources and being proud of making the community to have learning resources where people in the community or students in the area can enter to study and find knowledge

4. Conscious: Having consciousness mutually with villagers through data sets received from transferring in order to develop the data and organize knowledge to present viewpoints transferred from memories from the local people. The objective is to build common conscience to the youth in the area sustainably.

5. Characterize: Adapting and confronting situations to socialize are limited. This makes emotional and social learning difficult. However, developing learning resources based on the area-based approach makes it possible to see the image of social emotions, responding from one person to another person or another thing, bringing about following learning and adaptation.

1. Acceptance: Behaving oneself to accept culture or beliefs in areas where one enters to collect data

2. Communityship: Revise and study online knowledge and books to enter the study area and interview the owner of the memory history directly in the area. This also leads to learning about way of practice and absorbing communityship through having way of life like villagers in the community.

3. Extraction: Extract knowledge in entering the area to study area-based historical areas

4. Analysis and Synthetic: Analyze and synthesize data from unwritten evidences

5. Collaborative: Planning in entering the community area as well as having interactions among universities, temples and schools coordinating in bringing about cooperation

6. Redefine: Thinking about scaling up and connecting indigenous history to mainstream history to redefine localism

7. Development for all: Developing skills of lifelong learning in the $21^{\text {st }}$ century, namely skills of analytical thinking, skills of creating works, skills of working as at team and building relationships to people in the community area according to the standard frame of professional teachers to constructing social justice

Table 2 shows that the area-based social studies learning competency of social studies pre-service teachers have been developed indigenous history learning resources through area-based approach participatory action of social studies pre-service teachers for diversity students in Northern Thailand. This is an important competency in developing themselves of social studies pre-service teachers and a competency obtained from entering the field, area-based action an actual practice to study. The objective was to study and see the reality of educational management in the area in contexts resulting in making pre-service teachers have skills and knowledge from learning which students design and allocate the learning process by themselves. This can be summarized according to Figure 1. 


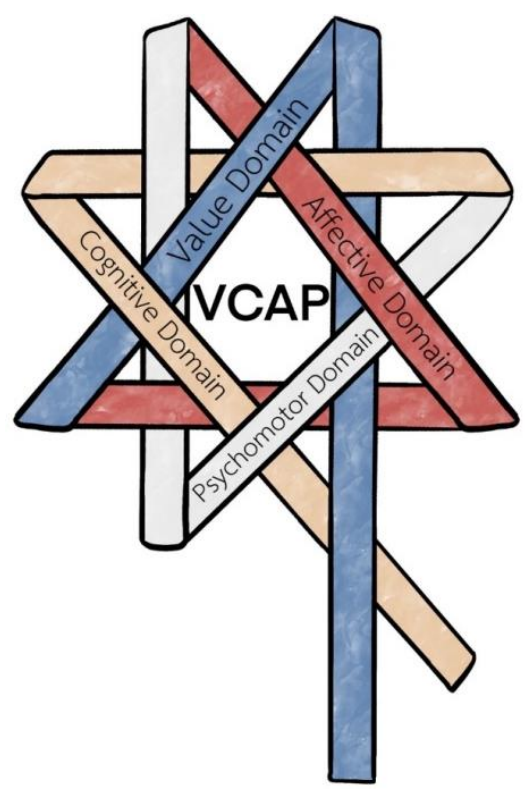

Figure 1. Competency of area-based social studies learning

Source: Charin Mangkhang (2022)

\section{Discussion}

The area-based action on the Viang Malika legend and Phra Nang Malika from indigenous history in the area of Mae Ai district, Chiang Mai province revealed that the community has the demand to develop learning resources telling its indigenous history through temples which are common areas in the community. The demand is to present indigenous history which is part of the historical development of the Lanna Kingdom in terms of business, politics, administration, education, religions, and the environment including women's roles as governesses or kings. This shows feminist concepts appearing on the page of indigenous history and reflects equality in stepping over physical limitations of the body (disability). The frame limiting gender is destroyed through the history of leaders and kings in indigenous history has influenced the development of the history of the historical development of the Thai local society up to the present time. This is consistent with Wongtangsawat (1985) explaining that Viang Malika is a small ancient city located in Mae Ai district, Chiang Mai province. It is 17 kilometers far from the Fang district. It lies between the district of village no. 8, no. 16 and no. 4. of Malika sub-district. The shape and the location of Viang Malika are similar to the ones of small cities appearing commonly in the North. It is characterized according to the form of the foothill plain where the city is located. Therefore, the city wall and the moat wind along with the characteristic of the area. Moreover, the work of Ano, (2006) indicates the Viang Malika is regarded as a local legend with cultural values and much importance to people in Mae Ai district because it is the story transferring history of the settlement of ancestors and ancient places of Mae Ai district. Viang Malika is a small ancient city. It is about 400 years old. Currently, there are brick ruins, city walls, and traces of the city moat left partly. From studying documents, research works, and entering the field in the community, it was found that the indigenous history of Viang Malika is an important history of the development of the Lanna Kingdom. Moreover, in the historical area of Viang Malika, there are remaining traces of historical shreds of evidence told through memories of people in Viang Malika later on. Developing indigenous history learning resources at this time is consistent with the work of Saisophon, et al. (2018) proposing viewpoints in the same direction by stating that learning resources are the place that gives information to the public, the resource where people can search knowledge according to their interests. They are learning resources outside the classroom making learners learn according to real conditions. As a result, this brings about bonding and appreciating things in the local community leading to mutual conservation for remaining further. Moreover, Chobyod (2019) proposes that indigenous history is the study of the history of the general people in the district or history of the mass society in the district not focusing on the history from the federal state power or explanation of cities or governors or important people of the city. Instead, it is the matter of investigating changes or movements of the way of life, cultures, politics, and economy of people in general in the local community. Indigenous history will give identity and self to the people in the local community. 
Indigenous history can be used to develop the district in terms of local education. The objective is to build a love for hometown and make people know the root and background of their own.

Developing indigenous history learning resources for diversity students in Northern Thailand through area-based participatory action learning of social studies pre-service teachers has brought about indigenous history learning resources integrating cooperation of universities, communities, temples, and schools, indigenous history learning resources promoting equal learning management. This is consistent with the study result of Boonyakarn (2011) stating that community learning resources originate from the wisdom and way of life of the community passed on. They are treasures of the community and important to economic and social development. Therefore, studying local data sources is important to local organizations, administration, planning, economy, society, education, research leading to innovation, living, seeking for knowledge, knowledge transferring, self-development of people, of the community and the society. Therefore, developing learning resources of the community requires conservation, storage, and transferring to the local community to acknowledge and bring about love and ties to local and national treasures. This is in line with the work of Supho, (2004) stating that allowing the community to be a learning resource, to have roles in teaching management for learners due to the closeness of the community is a good learning media. Besides the substance, allowing the people in the community to have roles in teaching learners will make them know and feel problems conditions regarding occurring environmental conditions in the community. As a result, learners will have knowledge and understanding about occurring problems. Moreover, Sriwilai, (2002) proposes that learning management in the wisdom content and community culture is something to do with learners in the community, which they should know. Allowing villagers to participate in the process of organizing activities makes villagers, who transfer knowledge by themselves, proud and happy with being able to benefit the community. They are also happy that there are people who can pass on wisdom. Moreover, training learners to know and to be able to operate wisdom works or to understand community cultures will make the community accept learners' abilities. This has a good effect on living in the community inters of understanding cultures. Learners will become the ones who pass on cultures further. Subwattana, (2011) proposes that indigenous history helps local people know themselves and build their local conscience to bring about localism. History of background and stories in the past of the community can tell that what the community could do or could not do, is afraid of or prefers, believes or does not believe and how to solve problems. All of these things have been collected to be wisdom and things passed on to the local people. Therefore, turning one's back on knowing the self of the local people is important for life in the future. Sattayanurak, (2015) reiterates the importance of studying indigenous history stating that without roots or community history, the community tends to lose energy in adaptation eventually and tends to become "community" without common conscience of being "community", resulting in several following problems. History will combine people in the community to have common conscience of having common roots in building indigenous history. This is not the history built by academicians or a small number of knowledgeable people in the community only but must be common conscience and consciousness of people in the community in terms of how they come and go and how they contribute to fighting with changes in the community until the community can progress up to the present time.

Distilling learned lessons obtained from developing local history resources through area-based participatory action learning of social studies pre-service teachers for diversity students in Northern Thailand made a discovery of the social studies pre-service teachers competence for 4 aspects so-called the competency of area-based social studies learning or "VCAP" consisting of 1) Value Domain, 2) Cognitive Domain 3) Affective Domain and 4) Psychomotor Domain. This helps promote the occupation competency of pre-service teachers to be more efficient. This is in line with Phuangphae, (2018) proposing that the competency of social studies teachers covers characteristics and behaviors showing knowledge, abilities, expertise in teaching social studies of professional teacher students. Moreover, Mekhiransiri, (1987) reiterates that regarding the teaching competency of social studies teachers, teachers must have teacher abilities in expressing behaviors influencing the physical, intellectual, emotional, and social progress of students. This is in line with the work of Panich (2015) stating that organizing activities of schooling for learners to practice, really touch, or to receive emotional experiences will help learners practice understanding values and lead to changing paradigms or thinking to be higher. Likewise, the work of Watcharanimit, Pimsan, \& Tanawutpornpinit (2020) proposes that developing teacher competency to have knowledge, abilities, to make teachers have potential in changing the process in organizing schooling through the design of learning based on the community can change teachers' attitudes to be people who are highly public conscience with virtues and ethics according to the principle of the teaching profession. They will love and be tied to the profession. They will be proud of being a teacher. The right development is to develop teachers to develop competency in self-development. Research results revealed important findings in terms of the fact that competency is regarded as an important thing of the teacher profession. It is both the working 
standard and the professional goal. Promoting competency to pre-service teachers before being in service will promote driving policies and mechanisms of reforming Thai area-based education and can develop the Thai educational system to be equity construction and challenges for global students.

\section{Conclusion}

Studying indigenous history will bring about the learning process to build educational equality through the social process with the cooperation of the school, the community, and the university. The objective is to develop indigenous history learning resources, which can be used in schooling management, organizing learning activities in the educational sandbox of Chiang Mai province. This can lead to developing qualities of area-based education according to the main goal of sustainable development further.

\section{Suggestions from the Research}

\subsection{Suggestions for Implementing Research Results}

Preparing documents to be database of historical data should be promoted and learning medias should be built in the community to bring about database and learning resources.

School administrators and community leaders should promote for cooperation among schools and the community in organizing periods of local study together with the community.

\subsection{Suggestions for Next Research}

The local curriculum for real life should be developed. The subject is the indigenous history of the Phra Nang Malika legend for the disabled and informal education. The objective is to build the learning process to extend tourism innovation and develop incomes for learners in the educational sandbox of Chiang Mai province.

The demand for developing the local curriculum integrating substance in social studies for ethnic learners in the area of indigenous history should be analyzed.

Results of using the indigenous history curriculum regarding the Phra Nang Malika legend promoting learning in the after digital society for learners in the educational sandbox of Chiang Mai province should be studied.

The community history curriculum should be developed to promote cultural tourism of the Fang Basin, Chiang Mai province.

\section{References}

Ano, S. (2006). Construction of Reading Promotion Book Titled Wiang Maliga Legend. Chiangmai: Chiangmai University.

Bickmore, K., \& Parker, C. (2014). Constructive conflict talk in classrooms: Divergent approaches to addressing divergent perspectives. Theory \& Research in Social Education, 42, 291-335. https://doi.org/10.1080/00933104.2014.901199

Black, L. M. (2011). History teaching today Approaches and methods. Council conseil of Europe: Printing Press.

Boonyakarn, C. (2011). Local information management. Research journal of Library of Thailand, 4(1), 1-12.

Chobyod, S. (2019). Indigenous history for sustainable and consolidated local development. King Prajadhipok's Institute Journal, 12(2), 115-138.

Daes, E. I. (2008). An overview of the history of indigenous peoples: self-determination and the United Nations. Cambridge Review of International Affairs, 21(1), 7-26. https://doi.org/10.1080/09557570701828386

Department of Fine Arts. (1981). Painting in the Rattanakosin period. Bangkok: Amarin Printing.

Kaewpanya, N., Mangkhang, C., \& Dibyamandala, J. (2021). Community-based Transdisciplinary Learning Innovation in Social Studies Through Miang Wisdom for Promoting Green Citizenship of Secondary School Students. Psychology and Education, 58(3), 875-884. https://doi.org/10. 17762/pae.v58i3.3020

Kearney, J., Wood, L., \& Zuber-Skerritt, O. (2013). Community-university partnerships using participatory action learning and action research (PALAR). Gateways: International Journal of Community Research and Engagement, 6, 113-130. https://doi.org/10.5130/ijcre.v6i1.3105

Kurti, R. S., Kurti, L. D., \& Fleming, L. (2014). The Philosophy of Educational Makerspaces Part I of Making an Educational Makerspaces. Teacher Librarian, 41(5), 8-11.

Lincoln, Y. S., \& Guba, E. G. (1985). Naturalistic Inquiry. California: Sage. https://doi.org/10.1016/0147-1767(85)90062-8 
Mahuika, N. (2019). Rethinking Oral History and Tradition: An Indigenous Perspective. UK: Oxford University Press. https://doi.org/10.1093/oso/9780190681685.001.0001

Mangkhang, C. (2017). Ideology: social studies curriculum for all. Bangkok: Chulalongkorn University.

Mangkhang, C. (2021). Learning Innovation of Area-Based Approach to Sustainable Development Goals of Highland Community Resources Management of Social Studies Teachers in the Northern Thailand. Higher Education Studies, 11(3), 95-107. https://doi.org/10.5539/hes.v11n3p95

Mangkhang, C., Wannapaisan, C., Jarupongputtana, C., \& Kaewpanya, N. (2021). Innovative of Indigenous history Learning Design Through Area-Based Approach of Social Studies Teachers to the Promoting Happiness Historical Consciousness of Basic Education Students in Northern Thailand. Turkish Online Journal of Qualitative Inquiry, 12(8), 3361-3378.

Mangkhang, C. (2021). Area-Based Approach to Local Curriculum Development on the History of Hariphunchai to Promote Happiness History Consciousness among Students in Hariphunchai Area, Lamphun Province (Research Report). Chiangmai: Chiangmai University.

Manichot, S. (1986). Thai Painting. Bangkok: Odeon Store Publishing House.

Mekhiransiri, W. (1987). The comparison of needs for enhancement of teaching competencies between social studied teachers in public and private secondary schools. Bangkok: Graduate School of Chulalongkorn University.

Ministry of Education. (2008). Basic Education Core Curriculum. Bangkok: Agricultural Cooperative Federation of Thailand.

Office of the National Economics and Social Development Council. (2018). National Economics and Social Development Plan 12th issue 2017-2021. Bangkok: Office of the Prime Minister.

Panich, W. (2015). Learn to change Transformative Learning. Bankok: S. R. Printing.

Phuangphae, P. (2018). A Development of instructional activities model based on constructivist theory and active learning for student teachers to enhance social studies teacher competencies. Nakhorn Prathom: Silpakorn University.

Saisophon, R. (2018). The Development of Learning Resources to the Informal Education Management of the Local Community in Chachoengsao Province (Research Report). Chachoengsao: Office of the Non-Formal and Informal Education.

Sattayanurak, A. (2015). Proposals for the study of indigenous history: the history of local communities in the northern region in Thanaphon. The godfather of the magician history collects historical articles on the occasion of the 60th anniversary of the celebration of Suntaravanich. Bangkok: Sayam.

Somdej, P. B. (2019). The Buddha Dharma amended edition. Bangkok: Mahachulalongkornrajavidyalaya University.

Sriwilai, N. (2002). Developing local curriculum on Karen Cloth Weaving subject for the lower secondary classroom at Mae Tuen Wittayakom school, Omkoi district, Chiang Mai province (Doctoral Dissertation). Chiang Mai University: Chiang Mai.

Subwattana, T. (2011). Concepts and approaches to the study of indigenous history (2nd ed.). Bangkok: Inthanin.

Supho, P. (2004). Using natural learning resources in school area for developing learning about natural and environment conservation (Master's Thesis). Srinakharinwirot University. Bangkok.

United Nation. (2015). Sustainable Development Golds: SDGs. Retrieved from https://www.un.org/sustainabledevelopment/sustainable-development-goals/

Watcharanimit, S., Pimsan, N., \& Tanawutpornpinit, S. (2020). Model for secondary school teacher competency development under the Office of Secondary Education Service Areas, Area 15. Journal of Buddhistic Sociology, 5(1), 14-25.

Wittayapak, C. (2003). History of the contestation for access to resources of Nan people. Bangkok: The Thailand Research Fund.

Wood, L. (2019). Participatory Action Learning and Action Research: Theory, Practice and Process. New York: Routledge. https://doi.org/10.4324/9780429441318

Wongtangsawat, N. (1985). Ancient community in Lanna area. Chiang Mai: Department of Geography, Faculty 
of Social Sciences, Chiang Mai University.

\section{Copyrights}

Copyright for this article is retained by the author(s), with first publication rights granted to the journal.

This is an open-access article distributed under the terms and conditions of the Creative Commons Attribution license (http://creativecommons.org/licenses/by/3.0/). 